\title{
The influence of different methods of soil processing on the microbial communities composition
}

\author{
Dmitriy Krasavin ${ }^{1 *}$, Andrey Gorovtsov ${ }^{2,3}$, and Evgeniy Krasavin ${ }^{1}$ \\ ${ }^{1}$ Don State Technical University, Gagarin sq., 1, Rostov-on-Don, 344003, Russia \\ ${ }^{2}$ Southern Federal University, Bolshaya Sadovaya, 105/42, Rostov-on-Don, 344006, Russia \\ ${ }^{3}$ Federal Rostov Agricultural Scientific Center, Institutskaya str., 1, Rostov region, Aksaysky district, \\ settl. Rassvet, 346735, Russia
}

\begin{abstract}
Modern agriculture faces the challenge of soil degradation due to improper land use and the development of erosion processes. Plowing technology profoundly transforms the surface soil horizon and makes it vulnerable to such negative processes. One of the technologies that reduce agricultural practices' negative impact on the soil is direct sowing, which is much more environmentally friendly than disking and plowing. In this work, the influence of different tillage technologies on the soil microbial community structure was studied. It was found that the number of cellulolytic, ammonifying bacteria, actinomycetes, and soil fungi was significantly higher when using direct sowing technology compared to plowing. The intensity of mineralization processes was lower than during plowing, which indicates a shift in the balance towards the accumulation of soil organic matter. Thus, the technology of direct sowing contributes to an increase in the soil biological activity and can be an effective method for restoring soil fertility.
\end{abstract}

\section{Introduction}

In the modern world, mankind is constantly faced with soil depletion due to its irrational use, water, and air erosion. This problem is also relevant for the Rostov region, whose residents frequently suffer from dust storms due to strong winds. One of the causes of wind erosion is the disturbance of the soil structure due to deep plowing in agricultural practice. To solve the problems caused by this technology's use, agricultural producers are switching to other soil cultivation technologies, among which the most common is disking. Less commonly used technology is no-till-direct sowing. Plowing technology is over 5,000 years old [1], and in comparison, direct sowing technology is entirely new, which raises many questions about its effectiveness and impact on the soil. Plowing includes mechanical treatment of soil up to $16 \mathrm{~cm}$ in depth over its entire surface including more than one mechanical treatment per season. Disking is based on the mechanical treatment of the soil to a depth of 5 to $15 \mathrm{~cm}$ over its entire surface with more than one mechanical treatment per season. Direct sowing is a technology for cultivating soil to a depth of $10 \mathrm{~cm}$, which

\footnotetext{
* Corresponding author: dina.krasavin@gmail.com
} 
performs mechanical cultivation directly on the crop residues and only in the sowing bed area and has only one mechanical soil cultivation per season [2]. The influence of this soil cultivation technology on the soil's biological activity, particularly on the microbial community's composition, is still not well understood.

The influence of soil cultivation methods on biological activity is reflected by the abundance of several trophic groups of culturable soil microorganisms. These groups of microorganisms are isolated within the microbial community following their trophic needs, which reflect their participation in various processes of mineralization and transformation of organic matter entering the soil. Cellulolytic bacteria take part in the decomposition of the plant residues entering the soil. The efficiency of decomposition of crop residues depends on their activity, which ensures the return of mineral nutrients to the soil in a form accessible to plants. Actinomycetes play an essential role in soil formation and maintenance of soil fertility. These bacteria are capable of transformation and decomposition of complex organic compounds (cellulose, humus, chitin, lignin, and others) inaccessible to many other microorganisms [3]. Aerobic spore-forming bacteria are known for their hydrolytic activity and can degrade complex biopolymers due to secreted exoenzymes. Besides, this group of bacteria can remain dormant for a long time in the form of endospores, returning to active reproduction when fresh organic substrates are supplied [4]. Among the bacteria involved in nitrogen-containing organic compounds transforming, the groups of ammonifiers and aminoautotrophs can be distinguished. The former use proteins and amino acids as energy substrates, promote nitrogen mineralization and increase their availability for other microorganisms and plants. The latter can assimilate mineral nitrogen compounds and synthesize proteins and nucleic acids from them [5]. These are prototrophic bacteria that do not require exogenous sources of amino acids and growth factors. The ratio of the number of these groups of bacteria reflects the dynamics of mineralization processes in the soil and is used to calculate the mineralization coefficient. Among the eukaryotic representatives of the microbial community, the number of mold fungi was studied since they, together with bacteria, take an active part in the decomposition of crop residues and participate in the formation of the soil structure and the pedogenesis process [6, 7].

The changes in the number of individual groups of soil microorganisms can form the basis of both the advantages and possible risks when applying zero tillage. This work aimed to compare the abundance of some groups of microorganisms in the soils with different cultivation technologies.

\section{Research object and materials}

In this work, a comparison of three different tillage technologies' effect on soil microorganisms' quantitative composition was made. These technologies, namely plowing, disking, and direct sowing, differ in the degree of mechanical impact on the soil. The crop cultivated in the previous season was winter wheat for all studied fields. The term of studied technologies used in the fields with direct sowing is one year, while disking and plowing are traditional agricultural practices that have been applied on for many years.

The studies were carried out on Haplic Chernozem. Sampling was carried out in December 2020 on agricultural fields after the autumn tillage. All studies were performed in triplicate, with the use of mixed soil samples, collected from the fields with different tillage technologies. 


\section{Materials and methods}

Soil sampling was carried out following GOST 17.4.4.02-2017. The soil was collected from a layer of $0-20 \mathrm{~cm}$. The mixed sample was formed from 10 sub-samples by mixing them. After sampling, the soil was immediately transported to the laboratory for microbiological analysis. The number of studied groups of microorganisms was determined by platecounting on nutrient media. The number of ammonifiers was determined on nutrient agar. Aminoautotrophs and actinomycetes were enumerated on starch-ammonia agar (ISP-4), mold fungi - on Czapek agar with the addition of streptomycin. To account for aerobic spore-forming bacteria, the method of pasteurization of the soil suspension at $80 \mathrm{C}$ for 20 minutes was used, followed by plating on nutrient agar mixed with an equal volume of $6^{\circ}$ Balling barley wort. To determine the abundance of cellulolytic bacteria, soil dilutions were inoculated on agar with carboxymethylcellulose as the only carbon source; after 4 days, agar plates were poured with iodine solution, and cellulolytic bacteria were counted according to the zones of carboxymethylcellulose hydrolysis. Soil moisture was determined by the gravimetric method after drying the soil to an absolutely dry state. Statistical data processing was performed using one-way analysis of variance with Tukey's test as a posthoc test. All calculations were carried out in the STATISTICA 12 software. Microsoft Excel 2007 was used to construct the diagrams.

\section{Results and discussion}

According to the studies results, a significant difference was noted in the structure of microbial communities of soils subjected to various types of mechanical treatment. Particularly striking differences were observed for cellulolytic bacteria and soil fungi (Fig. $1)$.
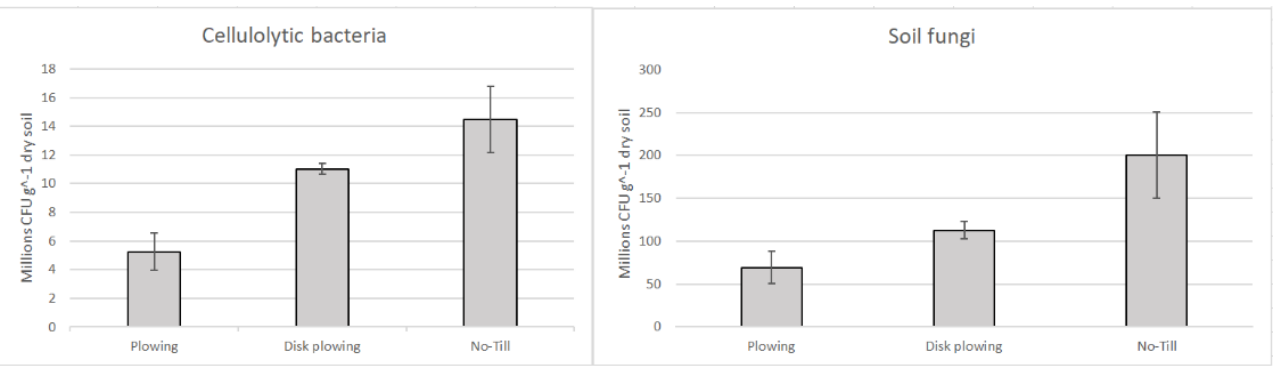

Fig. 1. The number of cellulolytic bacteria and fungi in soils with different types of mechanical treatment.

The results have shown that direct sowing technology leads to a significantly higher content of cellulolytic bacteria in the soil compared to disking and plowing. The high number of cellulolytic microbial communities ensures that crop residues leftover from the previous season will be decomposed and absorbed by other crops. This situation is associated with the concentration of plant residues in the upper soil layer, where optimal aeration conditions are created to ensure cellulolytic bacteria biomass growth. Simultaneously, the literature also describes opposite examples, when the number of cellulolytic bacteria in the surface soil layer during plowing turned out to be higher than with direct sowing technology and in fallow areas [8]. As for the number of mold fungi, their number has increased for the same reasons: among soil fungi, many species can decompose cellulose under aerobic conditions. 
An increase in the biological activity of the soil, and in particular the number of mold fungi when using direct sowing, was also noted in other works, and a four-fold increase in the number of soil fungi was observed in the upper soil layer after two years of no-till practice as compared to conventional tillage [9]. Simultaneously, an increase in the number of soil fungi may carry some risks, especially on soils with a high content of phytopathogenic fungi. Thus, the minimization of soil cultivation in Western Siberia conditions led to the domination of Fusarium species, which are the causative agents of root $\operatorname{rot}[10]$.

The abundance of ammonifying and aminoautotrophic bacteria was determined to study the influence of the soil cultivation method on the processes of nitrogen transformation (Fig. 2).
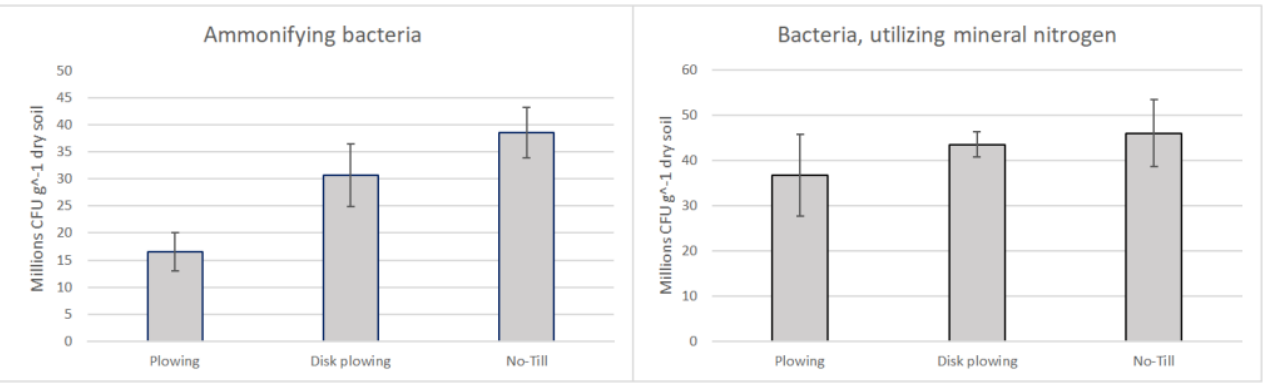

Fig. 2. The number of ammonifying and aminoautotrophic bacteria in soils with different types of mechanical treatment.

The results indicate that for the group of aminoautotrophs, there are no statistically significant differences between different types of soil cultivation. This is due to the lesser dependence of this group of microorganisms on the supply of fresh organic matter and their ability to use mineral forms of nitrogen. In contrast, the number of ammonifying bacteria involved in the mineralization of protein substrates and the decomposition of fresh plant residues was significantly $(\mathrm{p}=0.003)$ higher in the variant with direct sowing.

Based on the data on the number of ammonifiers and aminoautotrophs, the coefficient of mineralization was calculated, reflecting the direction of mineralization processes, that is, the balance between the content of organic and mineral forms of nitrogen available for microorganisms in the soil. With a more vigorous mineralization, the number of bacteria using mineral nitrogen increases [11].

The value of the mineralization coefficient on arable land was 2.43 , with disking it was 1.62 , and with direct sowing it was minimal and amounted to 1.37. These results suggest that under arable land conditions, microorganisms are forced to more actively use the organic compounds accumulated in the soil, while when minimizing soil cultivation, the balance is shifted towards the accumulation of organic compounds. This can contribute to the gradual restoration of the soil organic matter pool and the soil fertility restoration [12, $13,14]$. In connection with the influence of the soil cultivation method on the dynamics of mineralization processes, it was also important to assess changes in the group of aerobic spore-forming bacteria that take an active part in the hydrolysis of organic residues at later stages of their decay. The actinomycetes, that take part in the decomposition of complex biopolymers are also involved in the humification process to a large extent.

The number of actinomycetes and aerobic spore-forming bacteria is shown in Fig. 3. 

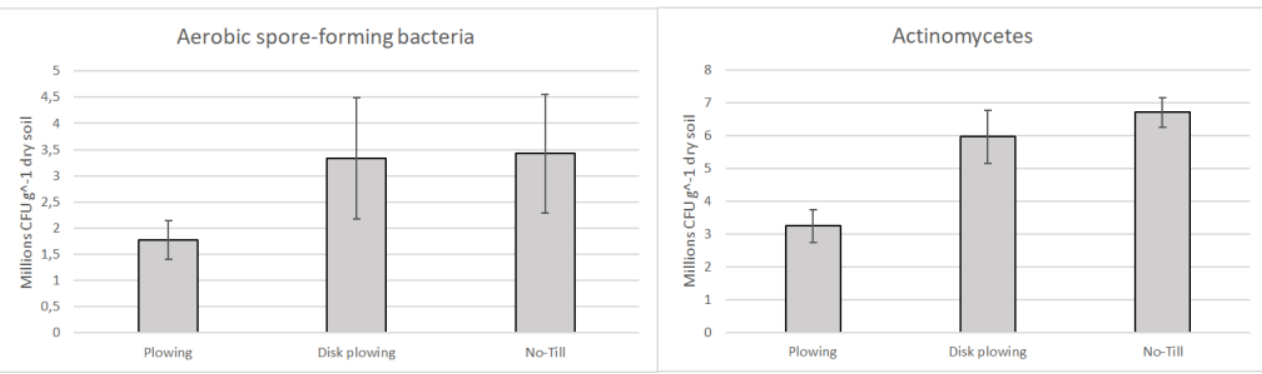

Fig. 3. The number of aerobic spore-forming bacteria and actinomycetes in soils with different types of mechanical treatment.

According to the data obtained, there is a significant increase in the number of actinomycetes in disking $(\mathrm{p}=0.003)$ and direct sowing $(\mathrm{p}=0.001)$ compared to plowing, but there are no differences between disking and direct sowing.

In addition to the observed changes in the number of particular groups of soil microorganisms, it was noted that in the soil from the fields, where direct sowing was used, higher moisture content of $22.65 \%$ was observed, compared with $20.8 \%$ for disking and $20.5 \%$ for plowing. It can be concluded that direct sowing is more effective in retaining moisture in the soil than the other two technologies. It is significant for the Rostov region, which is located in an area of insufficient moisture, and for which the reserves of soil moisture are often the determining factor for the final yield of cultivated crops [15].

The results obtained for Haplic chernozem under winter wheat are in good agreement with the results of other studies on other soils and crops. For example, Gałązka et al. [16] reported that while growing maize on podzolic soils, the direct sowing practice has led to increased glomalin content, indicating higher abundance of arbuscular mycorrhizal fungi. Reducing the extent of soil disturbance during tillage practice can significantly improve its biological activity: it has been shown, that microbial biomass carbon and nitrogen increased by up to $80 \%$, and there was a significant growth of dehydrogenase activity as compared to conventional ploughing [17].

The use of conservation agriculture in India, including zero-tillage practices for ricewheat and maize-wheat-mungbean crop rotation systems has led to significant improvements in both soil properties and biological activity. The soil parameters improvement included a reduction in soil bulk density, increase in soil organic carbon content. As for the soil biological parameters, the numbers of bacteria, fungi and actinomycetes were increased by $28 \%, 68 \%, 98 \%$, respectively [ 18$]$.

Similar results were obtained for sugar beet cultivation. In this case, the experiment design included comparing conventional ploughing, simplified cultivation and direct sowing. The results have shown a consistent increase of all microbiological parameters from ploughing to zero-till system [19].

Thus, regardless of the soil type or cultivated crop, there is a clear beneficial effect of reduced tillage on soil properties and biological activity, resulting in an overall increase of soil quality and health. It is particularly important for semi-arid areas, as zero-till practices could help to preserve the soil moisture and protect the soil uppermost layers from dessication and wind erosion. Many papers note an increase in soil organic carbon content which is an important finding in view of soil role as a global carbon pool. The increase in soil carbon content can indicate a turn from mineralization to the accumulation of soil organic matter, which can play a major role in global carbon sequestration and mitigating the climate changes originating from increasing carbon dioxide content in the atmosphere. Therefore, reduced tillage practices could be beneficial not only from the agricultural, but also from the global perspective [20-25]. 


\section{Conclusions}

Based on the results obtained, it can be concluded that direct sowing technology contributes to an increase in soils' biological activity compared to plowing and disking. In this case, the greatest increase is observed for the groups of microorganisms involved in soil organic matter transformation, namely, cellulolytic bacteria, ammonifiers, actinomycetes, and soil fungi. The improvement of biological activity contributes to the accumulation of humus and the restoration of soil fertility. Besides, this technology protects the soil from water and wind erosion, contributes to the preservation of soil moisture. Nevertheless, given the rapid development of soil fungi when using this technology, it is necessary to consider and carefully monitor the level of the infectious background for phytopathogenic fungi in the fields where it is used.

\section{References}

1. K. Lorenz, R. Lal, Recarbonization of the Biosphere (Springer, Dordrecht, 2012)

2. A. M. Izotov, E. N. Turin, E. L. Turina, et al., IOP Conf. Series: Earth Environ. Sci., 341(1), 012087 (2019)

3. A. A. Bhatti, S. Haq, R. A. Bhat, Microbial Pathogenesis, 111, 458-467 (2017)

4. R. G. Joergensen, F. Wichern, Soil Biology and Biochemistry, 116, 419-430 (2018)

5. A. Herrero, E. Flores, J. Imperial Ródenas, Encyclopedia of Microbiology, 3, 280-300 (2019)

6. U. Cavael, P. Tost, K. Diehl, et al., Soil Systems, 4(4), 70 (2020)

7. S. T. Lucas, E. M. D’Angelo, M. A. Williams, Applied Soil Ecology, 75, 13-23 (2014)

8. O. V. Kutovaya, A. M. Grebennikov, A. K. Tkhakakhova, et al., Bulletin of the V. V. Dokuchaev Soil Science Institute, 92, 35-61 (Article in Russian) (2018)

9. P. Lienhard, F. Tivet, A. Chabanne, et al., Agronomy for Sustainable Development, 33(2), 375-384 (2013)

10. E. Yu. Toropova, M. P. Selyuk, O. A. Kazakova, Agrochemistry, 5, 69-78 (Article in Russian) (2018)

11. V. Osipova, N. Buyankin, A. Krasnoperov, et al., EurAsian Journal of BioSciences, 14(1), 1933-1940 (2020)

12. F. T. Ramos, E. F. D. C. Dores, O. L. D. S. Weber, et al., Journal of the Science of Food and Agriculture, 98(9), 3595-3602 (2018)

13. T. B. Sapkota, M. Mazzoncini, P. Bàrberi, et al., Agronomy for Sustainable Development, 32(4), 853-863 (2012)

14. C. dos Reis Ferreira, E. C. da Silva Neto, M. G. Pereira, et al., Soil and Tillage Research, 198, 104533 (2020)

15. H. Zhao, Y. C. Xiong, F. M. Li, et al., Agricultural Water Management, 104, 68-78 (2012)

16. A. Gałązka, K. Gawryjołek, J. Grzhadziel, J. Ksiezak, Plant, Soil and Environment, 63(7), 300-306 (2017)

17. Z. Sándor, M. Tállai, I. Kincses, et al., DRC Sustainable Future, 1(1), 14-20 (2020)

18. M. Choudhary, H. S. Jat, A. Datta, et al., Applied Soil Ecology, 126, 189-198 (2018)

19. D. Swędrzyńska, S. Grześ, Polish Journal of Environmental Studies, 24(1), 285-294 (2015) 
20. Y. Lachuga, B. Akhalaya, Y. Shogenov, B. Meskhi, D. Rudoy, and A. Olshevskaya, IOP Conf. Ser.: Mater. Sci. Eng., 1001, 012121 (2020), doi:10.1088/1757899X/1001/1/012121

21. V. Pakhomov, T. Maltseva, N. Kulikova, et al., E3S Web Conf., 210, 07003 (2020), https://doi.org/10.1051/e3sconf/202021006012

22. B. Meskhi, V. Bondarenko, I. Efremenko, et al., E3S Web Conf., 217, 06012 (2020), https://doi.org/10.1051/e3sconf/202021706012

23. A. Soloviev, A. Matrosov, I. Panfilov, et al., E3S Web Conf., 210, 05017 (2020), https://doi.org/10.1051/e3sconf/202021005017

24. Y. Lachuga, B. Akhalaya, Y. Shogenov, et al., E3S Web Conf., 210, 08016 (2020), https://doi.org/10.1051/e3sconf/202021008016

25. D. Molochnikov, R. Khalimov, I. Gayaziev, et al., E3S Web Conf., 210, 08006 (2020), https://doi.org/10.1051/e3sconf/202021008006 